\title{
Investigations on Structural and Optical Properties of Hydrothermally Synthesized $\mathrm{Zn}_{2} \mathrm{SnO}_{4}$ Nanoparticles
}

\author{
L. Allwin Joseph, ${ }^{1}$ J. Emima Jeronsia, ${ }^{1}$ M. Mary Jaculine, ${ }^{2}$ and S. Jerome Das ${ }^{1}$ \\ ${ }^{1}$ Department of Physics, Loyola College, Chennai 600 034, India \\ ${ }^{2}$ Department of Physics, Velammal Engineering College, Chennai 600 066, India
}

Correspondence should be addressed to S. Jerome Das; jeromedas.s@gmail.com

Received 5 October 2015; Accepted 13 January 2016

Academic Editor: Ali Hussain Reshak

Copyright @ $2016 \mathrm{~L}$. Allwin Joseph et al. This is an open access article distributed under the Creative Commons Attribution License, which permits unrestricted use, distribution, and reproduction in any medium, provided the original work is properly cited.

\begin{abstract}
Ternary oxide $\mathrm{Zn}_{2} \mathrm{SnO}_{4}$ has emerged as a promising material due to its tunable work function, band gap energy, and electric resistivity by simply varying the composition of the material. Zinc stannate nanoparticles were synthesized by green hydrothermal growth technique at $200^{\circ} \mathrm{C}$ for the reaction time of $24 \mathrm{~h}$ using stannic chloride pentahydrate $\left(\mathrm{SnCl}_{4} \cdot 5 \mathrm{H}_{2} \mathrm{O}\right)$ and zinc chloride $\left(\mathrm{ZnCl}{ }_{2}\right)$ as precursors maintained at $\mathrm{pH}$ value of 8 . X-ray diffraction analysis confirmed the phase purity and high crystalline nature of the synthesized sample. The estimated crystallite size was about $12.3 \mathrm{~nm}$ corresponding to the most prominent plane (311) using Scherrer equation. Morphology of the sample was characterized by SEM analysis, which confirmed the presence of small size nanoparticles. The optical property of synthesized sample was studied by using UV-visible and PL spectroscopy analysis. The derived optical band gap of $3.94 \mathrm{eV}$ was found to be blue shifted as compared to bulk $\mathrm{Zn}_{2} \mathrm{SnO}_{4}(3.6 \mathrm{eV})$, which should be attributed to the quantum size effects. Room temperature photoluminescence spectrum showed emission bands at $397 \mathrm{~nm}$ and $468 \mathrm{~nm}$.
\end{abstract}

\section{Introduction}

Ternary oxide zinc stannate $\left(\mathrm{Zn}_{2} \mathrm{SnO}_{4}\right)$ has fascinated massive interest of research due to their exceptional electrical and optical properties [1]. $\mathrm{Zn}_{2} \mathrm{SnO}_{4}$ has larger band gap of $3.6 \mathrm{eV}$ and higher electron mobility $\left(10-15 \mathrm{~cm}^{2} \mathrm{~V}^{-1} \mathrm{~S}^{-1}\right)[1-5]$. Ternary oxide materials are of superior property compared to binary oxides owing to their freedom to tune the properties such as work function, electrical conductivity, and band gap energy by varying its composition $[1,3]$. Zinc tin oxide exists in two phases $\mathrm{Zn}_{2} \mathrm{SnO}_{3}$ and $\mathrm{Zn}_{2} \mathrm{SnO}_{4}$ where $\mathrm{Zn}_{2} \mathrm{SnO}_{3}$ is a metastable form having face centred cubic perovskite structure which occurs at the temperature range of $300^{\circ} \mathrm{C}$ $500^{\circ} \mathrm{C}$. Above $600^{\circ} \mathrm{C}$ it transforms to stable $\mathrm{Zn}_{2} \mathrm{SnO}_{4}$ with cubic spinel structure [6-10].

The precursor materials of zinc stannate were abundant and of low cost which point out this material for wide range of applications. Owing to its feasible property, $\mathrm{Zn}_{2} \mathrm{SnO}_{4}$ has prospective applications such as photocatalysis, transparent conducting oxides, sensors, and lithium ion batteries and in case of dye sensitized solar cells (DSSC), $\mathrm{Zn}_{2} \mathrm{SnO}_{4}$ provides better control of carrier transport and collection which recovers the long term chemical stability of DSSC $[2,3,10-12]$. There are many techniques to synthesize $\mathrm{Zn}_{2} \mathrm{SnO}_{4}$ thermal evaporation, pulse laser deposition, spray pyrolysis, sputtering technique, and so forth [2], which requires extremely sophisticated laboratory and power consumption; thus in our case we utilized hydrothermal technique. The materialization of $\mathrm{Zn}_{2} \mathrm{SnO}_{4}$ nanoparticles via hydrothermal process requires main processing variables such as reaction temperature and time, mineralizers enabling the formation reaction, and the $\mathrm{pH}$ of the slurry reaction in the autoclave. The mineralizer controls the nucleation sites at the specific $\mathrm{pH}$ which leads to the formation of $\mathrm{Zn}_{2} \mathrm{SnO}_{4}$ nanoparticles. Normally $\mathrm{NaOH}$ was used as a mineralizer and it has some drawbacks, when the concentration of $\mathrm{NaOH}$ is less the major phase forms will be $\mathrm{SnO}_{2}$. In the meantime at higher $\mathrm{pH}$ value the formation of $\mathrm{ZnO}$ phase occurs rather than the formation of $\mathrm{Zn}_{2} \mathrm{SnO}_{4}$ [13-15]. In the present work, hydrazine hydrate was used in the hydrothermally synthesized $\mathrm{Zn}_{2} \mathrm{SnO}_{4}$ nanoparticles. 


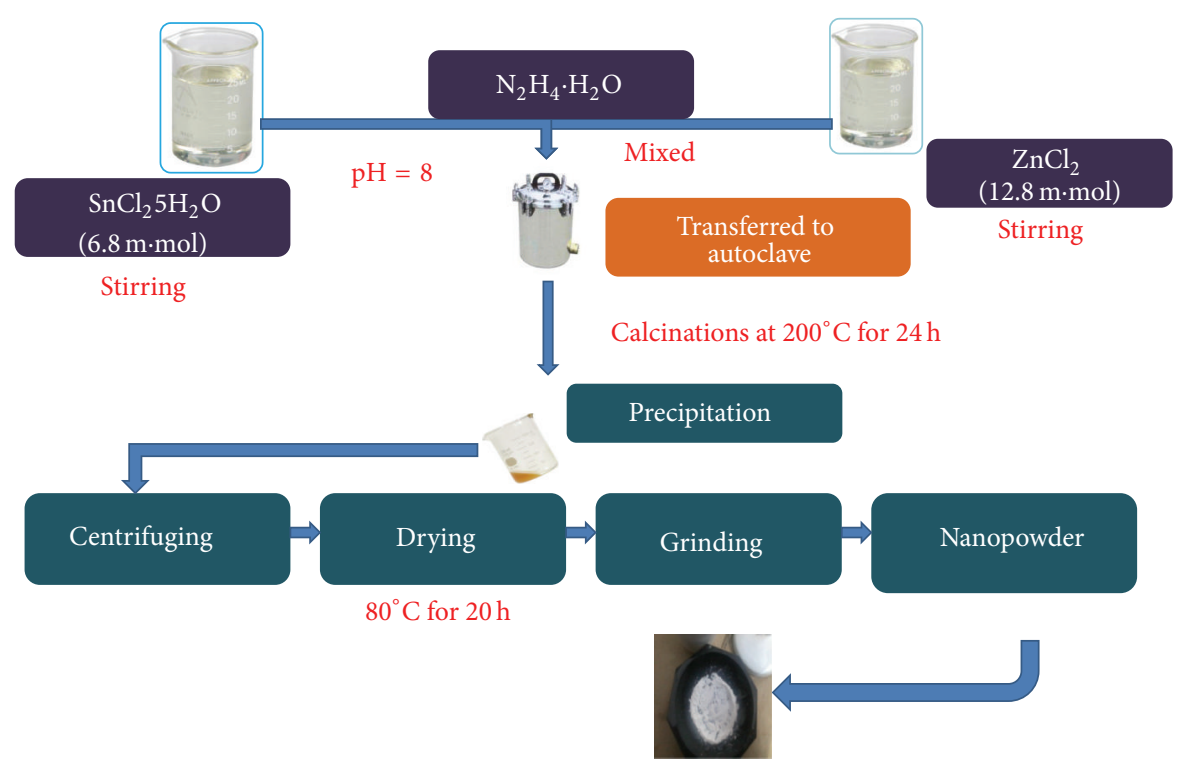

FIGURE 1: Schematic representation of hydrothermal synthesis of zinc stannate nanoparticles.

Hydrazine hydrate acts as a complex agent for effective control over the size of the nanoparticles with high crystallinity. Zhu et al. reported ultrafine $\mathrm{Zn}_{2} \mathrm{SnO}_{4}$ nanorods of 2-4 nm diameter using hydrazine hydrate [16]. The characterization studies like X-ray diffraction studies, UV-vis spectral analysis, photoluminescence studies, and SEM analysis were carried out to analyze the structural, optical, and morphological of the synthesized $\mathrm{Zn}_{2} \mathrm{SnO}_{4}$ nanoparticles.

\section{Experimental Details}

2.1. Preparation of $\mathrm{Zn}_{2} \mathrm{SnO}_{4}$ Nanoparticles Using Hydrazine Hydrate as a Mineralizer. All chemicals were used without any further purification. The zinc chloride has been used as a source of $\mathrm{Zn}$, tin chloride pentahydrate was used as a source of tin, and hydrazine hydrate was acting as an oxidizing agent. All chemicals used were of analytical grade. Ultrapure double distilled water was used for all dilution and sample preparation. For the synthesis of $\mathrm{Zn}_{2} \mathrm{SnO}_{4}$ nanoparticles using hydrazine hydrate as a mineralizer, hydrothermal technique was utilized. In a typical procedure, the ratio of $\mathrm{Zn}: \mathrm{Sn}: \mathrm{N}_{2} \mathrm{H}_{2} \mathrm{H}_{2} \mathrm{O}$ was $2: 1: 8$. Zinc chloride, tin chloride pentahydrate were dissolved into distilled water to form transparent solution under magnetic stirring for $3 \mathrm{~h}$. Hydrazine hydrate was then added dropwise into the mixture to form white slurry. The precursors were maintained at $\mathrm{pH}$ value of 8 . After stirring for $30 \mathrm{~min}$, the final mixture was transferred into a Teflon line stainless steel autoclave with a filling capacity of $80 \%$. The autoclave was maintained at $200^{\circ} \mathrm{C}$ for $24 \mathrm{~h}$ and cooled naturally to room temperature. To obtain powder samples, the resulting nanoparticles were separated by centrifugation from the reaction solution and washed repeatedly with deionized water and ethanol. Finally the washed particles were dried at $80^{\circ} \mathrm{C}$ for $20 \mathrm{~h}$ to get the powdered sample. The obtained $\mathrm{Zn}_{2} \mathrm{SnO}_{4}$ powder sample was grinded for $1 \mathrm{~h}$ using agate mortar. Figure 1 shows the schematic diagram of preparation of $\mathrm{Zn}_{2} \mathrm{SnO}_{4}$ nanoparticles via hydrothermal technique. The prepared sample was given for its identification and characterization to different instrumentation techniques.

2.2. Characterization Methods. The resulting sample of $\mathrm{Zn}_{2} \mathrm{SnO}_{4}$ nanoparticles was characterized by X-ray diffraction analysis (XRD) (RigakuD/max2500) with $\mathrm{Cu} \mathrm{K} \mathrm{K}_{\alpha}(\lambda=$ $1.5418 \AA$ Á) radiation. The morphology and microstructure of $\mathrm{Zn}_{2} \mathrm{SnO}_{4}$ nanoparticles were studied by scanning electron microscopy (SEM). The optical properties were analyzed using UV spectral studies and photoluminescence (PL) analysis.

\section{Result and Discussion}

3.1. X-Ray Diffraction Analysis. The powder XRD analysis was carried out using powder X-ray diffractometers with $\mathrm{Cu}$ $\mathrm{K}_{\alpha}(\lambda=1.5418 \AA \AA$ ) radiation. The intensity versus $2 \theta$ values was recorded between the ranges $10-70^{\circ}$. The recorded XRD spectrum of the synthesized sample zinc stannate $\left(\mathrm{Zn}_{2} \mathrm{SnO}_{4}\right)$ is shown in Figure 2.

There are eight prominent peaks found between the 10 and $70^{\circ}$ range which signifies the formation of cubic spinel structure phase of $\mathrm{Zn}_{2} \mathrm{SnO}_{4}$ without any byproducts phases such as $\mathrm{SnO}_{2}$ and $\mathrm{ZnO}$. The phase formation of $\mathrm{Zn}_{2} \mathrm{SnO}_{4}$ was good in agreement with JCPDS Powder Diffraction File number 74-2184. The estimated average crystallite size $\mathrm{Zn}_{2} \mathrm{SnO}_{4}$ is $14.99 \mathrm{~nm}$. The $2 \theta$ values of the peaks and their corresponding intensity and the $h k l$ values were given in Table 1.

The average crystallite sizes for all the samples were calculated from FWHM using Scherrer formula $D=$ $K \lambda / \beta \cos \theta$, where $k=0.9$ (shape factor), $\lambda$ was the $\mathrm{X}$ ray wavelength $(1.5406 \AA)$, and $\beta$ was the full width half 
TABLE 1: The variations at different plane of $\mathrm{Zn}_{2} \mathrm{SnO}_{4}$ nanoparticles.

\begin{tabular}{lccccc}
\hline Position $2 \theta$ (degree) & Intensity (a.u.) & $\beta$ (radians) & $h k l$ & Relative intensity (a.u) & Crystallite size (nm) \\
\hline 29.166 & 21.067 & 0.45 & 220 & 24.79 & 19.06 \\
34.49 & 84.94 & 0.70 & 311 & 100 & 12.3 \\
35.92 & 25.28 & 0.74 & 222 & 29.76 & 11.79 \\
41.82 & 18.62 & 0.9 & 400 & 51.92 & 9.87 \\
55.20 & 28.45 & 0.6 & 43.49 & 15.61 \\
60.66 & 41.06 & 0.45 & 440 & 48.34 & 21.36 \\
\hline
\end{tabular}

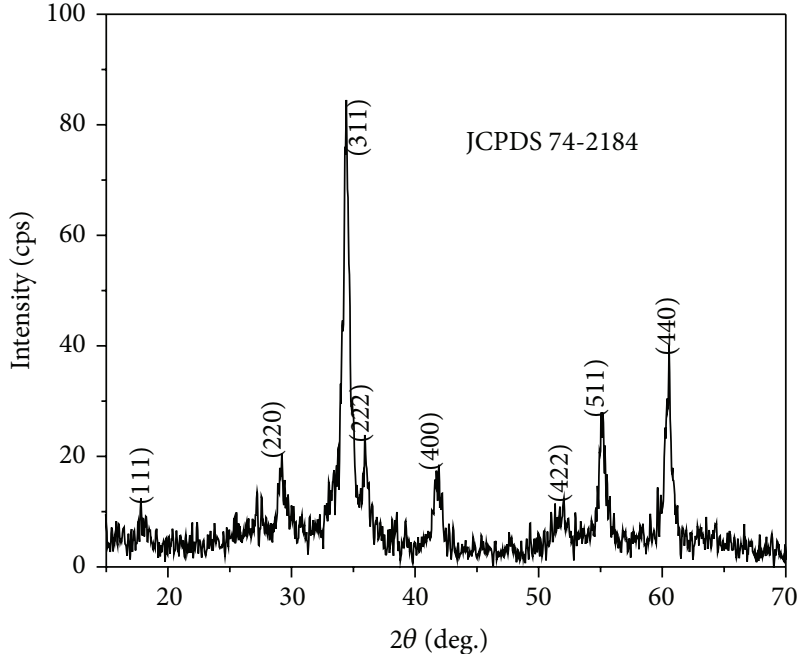

FIGURE 2: XRD pattern of synthesized $\mathrm{Zn}_{2} \mathrm{SnO}_{4}$ nanoparticles.

maximum (FWHM) of the diffraction line. The graph was plotted between crystallite size and their corresponding $2 \theta$ values of the diffraction peaks in Figure 3.

3.1.1. Williamson Hall Method. Crystal imperfections and distortion which arises from strain induced broadening are related by

$$
\varepsilon=\frac{\beta_{s}}{\tan \theta} .
$$

The Williamson Hall method does not follow $1 / \cos \theta$ dependence as in the Scherrer formula but instead it varies with $\tan \theta$. This allows a fundamental difference for a separation of reflection broadening. Thus both size and strain enlargements are additive components of the total integral breadth of the peak. The Bragg angle $\theta$ dependency of both size and strain broadening was dealt in the investigation of $\mathrm{W}-\mathrm{H}$ method $[17,18]$ :

$$
\begin{aligned}
& \beta=\beta_{s}+\beta_{D}, \\
& \beta=\frac{k \lambda}{\beta \cos \theta}+4 \varepsilon \tan \theta .
\end{aligned}
$$

Rearranging the term gives

$$
\beta \cos \theta=\frac{k \lambda}{\beta}+4 \varepsilon \sin \theta .
$$

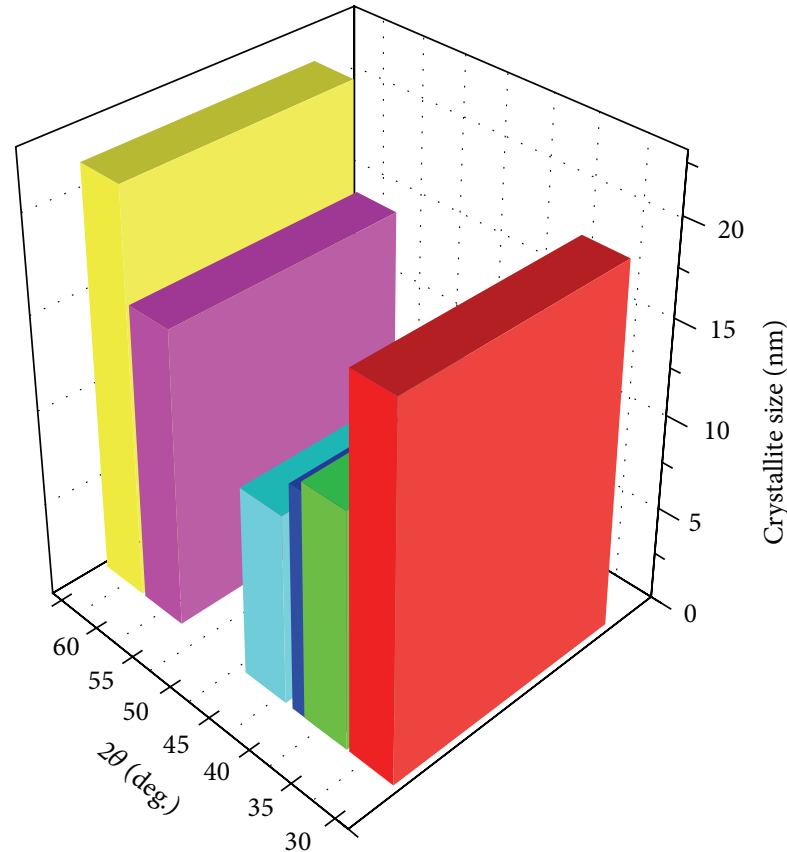

FIgURE 3: The bar graph between $2 \theta$ values and corresponding crystallite sizes of synthesized $\mathrm{Zn}_{2} \mathrm{SnO}_{4}$ nanoparticles.

Equation (3) represents the UDM (Uniform Deformation Model), where the strain was assumed to be uniform in all crystallographic directions, thus considering the isotropic nature of crystal, where all the material properties are independent of the direction along which they are measured.

The plot was drawn taking the term $\beta \cos \theta$ along the $y$-axis and $4 \sin \theta$ along $x$-axis for the chosen orientation of the peaks of $\mathrm{Zn}_{2} \mathrm{SnO}_{4}$ cubic spinel phase. The slope and the intercept of the least square fitted line represent strain and crystallite size, respectively $[17,18]$. The Williamson hall plot of least square fitted was shown in Figure 4. The scattered points corresponding to each crystallographic plane in the W-H plot can be attributed to the anisotropy of the dislocation strain field in the elastic medium, as well as to the contribution of planar defects [19]. The crystallite size and the strain were found to be $15.65 \mathrm{~nm}$ and $\approx 0.0021$, respectively.

3.2. UV-Vis Spectral Analysis. The spectroscopic properties of any given sample can be understood by analyzing its UV-vis spectra. The absorption spectra were recorded in 


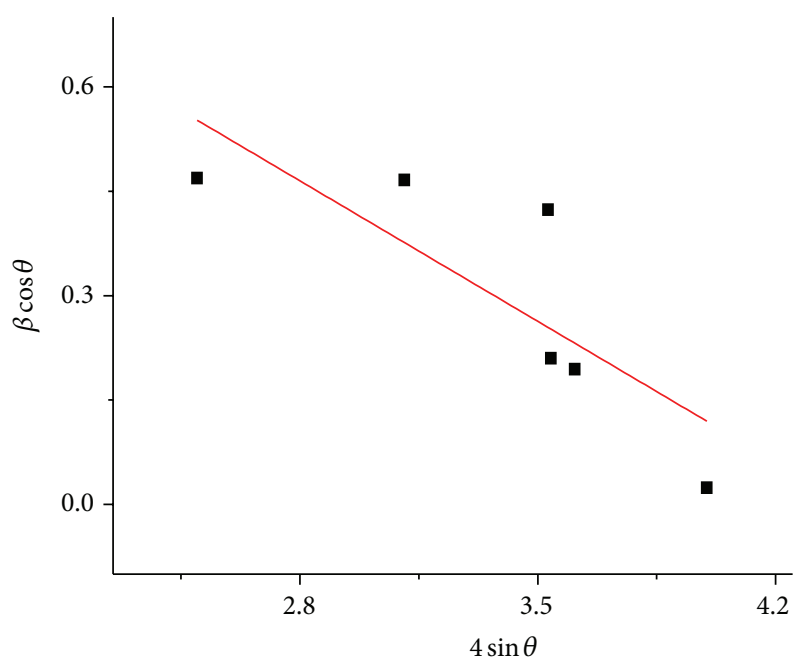

FIGURE 4: Least square fitted W-H plot assuming UDM.

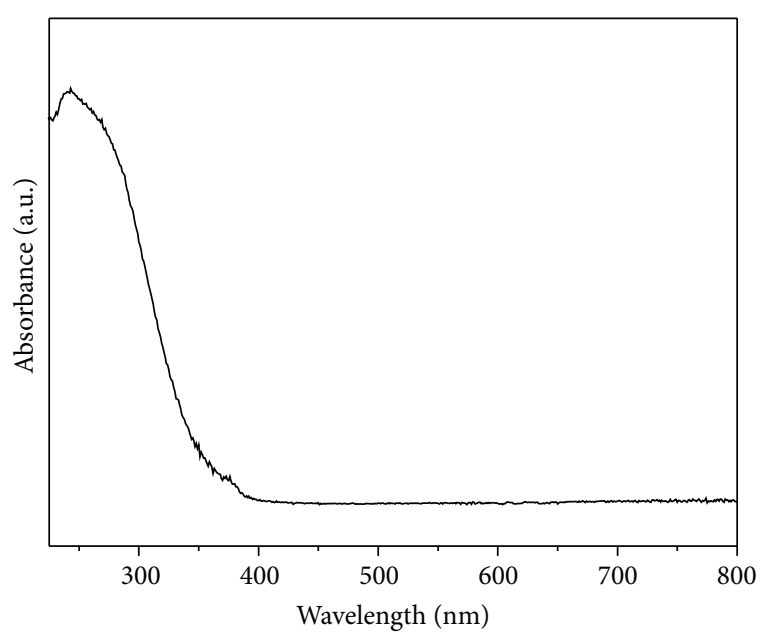

FIGURE 5: UV-vis spectrum of zinc stannate $\mathrm{Zn}_{2} \mathrm{SnO}_{4}$ nanoparticles.

the wavelength range of $200-800 \mathrm{~nm}$ on a Varian Cary 500 Spectrophotometer.

Figure 5 shows the absorption spectra of $\mathrm{Zn}_{2} \mathrm{SnO}_{4}$ nanoparticles synthesized by hydrothermal method. The absorption edge is found to be centered around $240 \mathrm{~nm}$ for $\mathrm{Zn}_{2} \mathrm{SnO}_{4}$ samples, beyond which the sample is completely transparent. The absorption band gap energy is determined using the Tauc formula [20] given by $(\alpha h \nu)^{1 / n}=K(h \nu-$ $E_{g}$ ), where $\alpha$ is the absorption coefficient, $h \nu$ is the photon energy, $K$ is a constant relative to the material, and $\mathrm{n}$ is the nature of transition in a semiconductor material. A plot of $(\alpha h \nu)^{2}$ versus $(h \nu)$ is used to evaluate the direct optical band gap of the material. Figure 6 shows the Tauc plot for both the synthesized samples. The band gap is determined by extrapolating the linear portion of the curve. The band gap was found to be $3.94 \mathrm{eV}$ for samples synthesized $\mathrm{Zn}_{2} \mathrm{SnO}_{4}$ nanoparticles. The derived optical band gap of $3.94 \mathrm{eV}$ was found to be blue shifted as compared to bulk $\mathrm{Zn}_{2} \mathrm{SnO}_{4}$

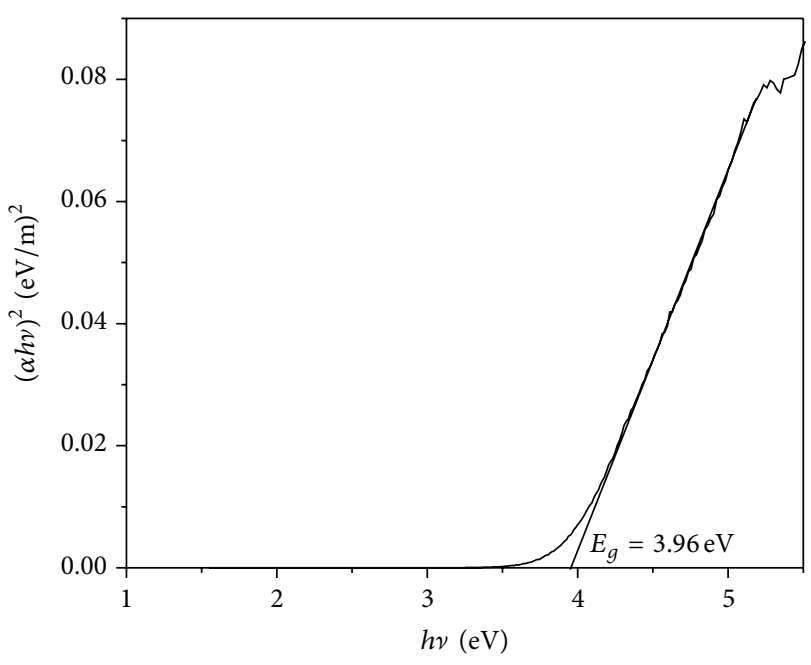

Figure 6: Tauc plot of $\mathrm{Zn}_{2} \mathrm{SnO}_{4}$ nanoparticles.

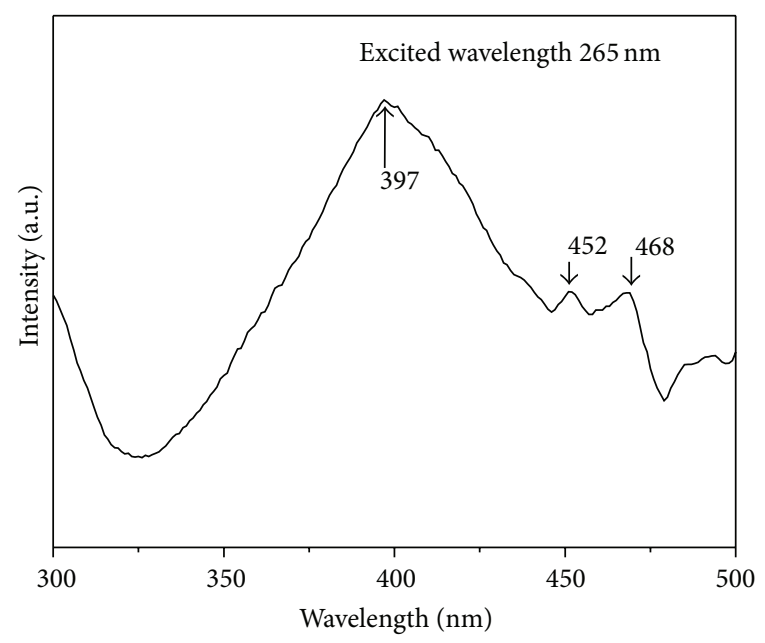

FIGURE 7: Photoluminescence spectrum of $\mathrm{Zn}_{2} \mathrm{SnO}_{4}$ nanoparticles.

$(3.6 \mathrm{eV})$, which should be attributed to the quantum size effects, thus extending its absorption into the visible region.

3.3. Photoluminescence Study. The room temperature PL measurements were done on a Jobin Yvon Fluorolog-3-11 Spectrofluorometer with a $450 \mathrm{~W}$ Xenon Lamp as source. Figure 7 shows the room temperature PL spectra recorded for $\mathrm{Zn}_{2} \mathrm{SnO}_{4}$ samples for a wavelength range of $250-500 \mathrm{~nm}$. The emission peaks were recorded at an excitation wavelength of $265 \mathrm{~nm}$. The spectra show strong emission band centered around $397 \mathrm{~nm}$, and two weak emission bands centred at $452 \mathrm{~nm}$ and $468 \mathrm{~nm}$ which may be attributed to the oxygen vacancies. The band gap of the bulk zinc stannate is $3.6 \mathrm{eV}$; therefore we expect the band edge emission in the UV region. In our case, we perceive blue emission in the weak band region of $452 \mathrm{~nm}$ and $468 \mathrm{~nm}$ because during annealing zinc stannate, luminescence centres like oxygen vacancies and crystal defect occur and it is not due to band-to-band transition. These luminescent centres give new energy levels in 


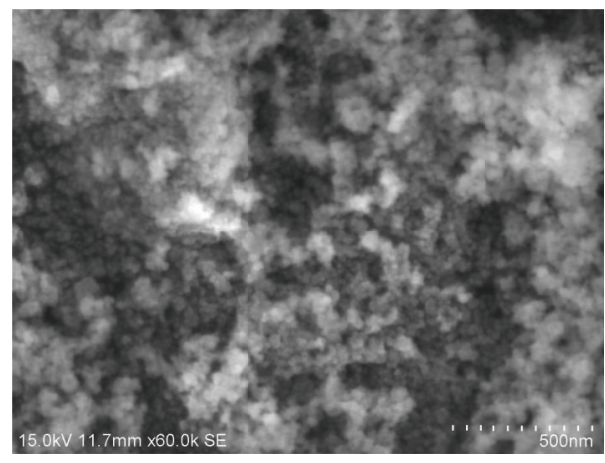

FIGURE 8: SEM micrographs of the $\mathrm{Zn}_{2} \mathrm{SnO}_{4}$ nanoparticles.

the band gap of $\mathrm{Zn}_{2} \mathrm{SnO}_{4}$ as reported in Fu et al. The photoexcited hole with an electron was recombined and occupied by the new energy level which yields the blue emission [21].

3.4. Morphological Analysis. The images of surface morphology were captured at a voltage of $15 \mathrm{kV}$ on a Hitachi SU6600 SEM instrument. Figure 8 shows the SEM image for $\mathrm{Zn}_{2} \mathrm{SnO}_{4}$ nanoparticles. Figure 8 displays the synthesized powder in the form of polydisperse and roughly spherical particles with their sizes ranging about $\sim 25-30 \mathrm{~nm}$. The SEM micrograph magnification illustrates that the surface of the synthesized $\mathrm{Zn}_{2} \mathrm{SnO}_{4}$ nanoparticles is rough and porous as they are comprised of numerous nanoparticles, these contact closely, and therefore many porous holes can be observed. When compared with the powder X-ray size the value is quite high and this can be accredited to high agglomeration of particles.

\section{Conclusion}

In summary, using hydrazine hydrate as a mineralizer zinc stannate was successfully synthesized via hydrothermal method. The cubic spinel structure was confirmed using powder X-ray diffraction analysis. Scherrer equation was utilized to calculate the crystalline size of the $\mathrm{Zn}_{2} \mathrm{SnO}_{4}$ nanoparticles and it was instigated to be $14.99 \mathrm{~nm}$. The crystalline size was also calculated by using Williamson Hall method and the value is $15.65 \mathrm{~nm}$. The optical properties were investigated by UV-visible and PL spectroscopy analysis. The optical band gap was found to be $3.94 \mathrm{eV}$ and blue shifted as compared to bulk $\mathrm{Zn}_{2} \mathrm{SnO}_{4}(3.6 \mathrm{eV})$, which is ascribed to the quantum size effects. Photoluminescence spectrum showed emission bands at $397 \mathrm{~nm}$ at room temperature. The two weak emissions in the PL spectrum band centred at $452 \mathrm{~nm}$ and $468 \mathrm{~nm}$ which may be accredited to the oxygen vacancies. The roughly spherical particles were attained with the particle sizes ranging about $\sim 25-30 \mathrm{~nm}$. Thus, the obtained $\mathrm{Zn}_{2} \mathrm{SnO}_{4}$ nanoparticles were suitable for applications such as sensors, optoelectronic devices, and solar cells.

\section{Conflict of Interests}

The authors declare that there is no conflict of interests regarding the publication of this paper.

\section{Acknowledgment}

The authors are deeply indebted to the Department of Physics, Loyola College, Chennai, for providing laboratory facility to carry out this work.

\section{References}

[1] P. Jayabal, V. Sasirekha, J. Mayandi, and V. Ramakrishnan, "Microwave assisted synthesis of zinc stannate nanocubes for dye sensitized solar cell application," Superlattices and Microstructures, vol. 75, pp. 775-784, 2014.

[2] C. Chen, G. Li, J. Li, and Y. Liu, "One-step synthesis of 3D flower-like $\mathrm{Zn}_{2} \mathrm{SnO}_{4}$ hierarchical nanostructures and their gas sensing properties," Ceramics International, vol. 41, no. 1, pp. 1857-1862, 2015.

[3] Z. Li, Y. Zhou, H. Yang, R. Huang, and Z. Zou, "Nanosheetassembling hierarchical zinc stannate microspheres for enhanced efficiency of dye-sensitized solar cells," Electrochimica Acta, vol. 152, pp. 25-30, 2015.

[4] T. J. Coutts, D. L. Young, X. Li, W. P. Mulligan, and X. $\mathrm{Wu}$, "Search for improved transparent conducting oxides: a fundamental investigation of $\mathrm{CdO}, \mathrm{Cd}_{2} \mathrm{SnO}_{4}$, and $\mathrm{Zn}_{2} \mathrm{SnO}_{4}$," Journal of Vacuum Science \& Technology A, vol. 18, no. 6, pp. 2646-2660, 2000.

[5] M. Mary Jaculine, S. Jerome Das, H.-J. Kim, B. C. Kim, K.-H. $\mathrm{Yu}$, and C. Justin Raj, "Zinc stannate nanoneedles for CdS/CdSe quantum dot sensitized solar cells," Materials Letters, vol. 111, pp. 28-31, 2013.

[6] T. Lana-Villarreal, G. Boschloo, and A. Hagfeldt, "Nanostructured zinc stannate as semiconductor working electrodes for dye-sensitized solar cells," Journal of Physical Chemistry C, vol. 111, no. 14, pp. 5549-5556, 2007.

[7] W. Cun and W. Xinming, "Synthesis, characterization and photocatalytic property of nano-sized $\mathrm{Zn}_{2} \mathrm{SnO}_{4}$," Journal of Materials Science, vol. 37, no. 14, pp. 2989-2996, 2002.

[8] J. Wang, X. W. Sun, S. Xie, W. Zhou, and Y. Yang, "Singlecrystal and twinned $\mathrm{Zn}_{2} \mathrm{SnO}_{4}$ nanowires with axial periodical structures," Crystal Growth \& Design, vol. 8, no. 2, pp. 707-710, 2008.

[9] D. W. Kim, S. S. Shin, I. S. Cho et al., "Synthesis and photovoltaic property of fine and uniform $\mathrm{Zn}_{2} \mathrm{SnO}_{4}$ nanoparticles," Nanoscale, vol. 4, no. 2, pp. 557-562, 2012.

[10] B.-Y. Wang, H.-Y. Wang, Y.-L. Ma, X.-H. Zhao, W. Qi, and Q.-C. Jiang, "Facile synthesis of fine $\mathrm{Zn}_{2} \mathrm{SnO}_{4}$ nanoparticles/graphene composites with superior lithium storage performance," Journal of Power Sources, vol. 281, pp. 341-349, 2015.

[11] W. Wang, H. Chai, X. Wang, X. Hu, and X. Li, "Ethanol gas sensing performance of $\mathrm{Zn}_{2} \mathrm{SnO}_{4}$ nanopowder prepared via a hydrothermal route with different solution $\mathrm{pH}$ values," Applied Surface Science, vol. 341, pp. 43-47, 2015.

[12] M. M. Jaculine, C. J. Raj, H.-J. Kim, A. J. Rajendran, and S. J. Das, "Zinc stannate nanoflower $\left(\mathrm{Zn}_{2} \mathrm{SnO}_{4}\right)$ photoanodes for efficient dye sensitized solar cells," Materials Science in Semiconductor Processing, vol. 25, pp. 52-58, 2014.

[13] A. Annamalai, D. Carvalho, K. C. Wilson, and M.-J. Lee, "Properties of hydrothermally synthesized $\mathrm{Zn}_{2} \mathrm{SnO}_{4}$ nanoparticles using $\mathrm{Na}_{2} \mathrm{CO}_{3}$ as a novel mineralizer," Materials Characterization, vol. 61, no. 9, pp. 873-881, 2010.

[14] A. Annamalai, Y. D. Eo, C. Im, and M.-J. Lee, "Surface properties and dye loading behavior of $\mathrm{Zn}_{2} \mathrm{SnO}_{4}$ nanoparticles 
hydrothermally synthesized using different mineralizers," Materials Characterization, vol. 62, no. 10, pp. 1007-1015, 2011.

[15] J. Fang, A. Huang, P. Zhu et al., "Hydrothermal preparation and characterization of $\mathrm{Zn}_{2} \mathrm{SnO}_{4}$ particles," Materials Research Bulletin, vol. 36, no. 7-8, pp. 1391-1397, 2001.

[16] H. Zhu, D. Yang, G. Yu, H. Zhang, D. Jin, and K. Yao, "Hydrothermal synthesis of $\mathrm{Zn}_{2} \mathrm{SnO}_{4}$ nanorods in the diameter regime of sub-5 $\mathrm{nm}$ and their properties," The Journal of Physical Chemistry B, vol. 110, no. 15, pp. 7631-7634, 2006.

[17] Y. T. Prabhu, K. V. Rao, V. S. S. SaiKumar, and B. S. Kumari, "Xray analysis by Williamson-Hall and size-strain plot methods of $\mathrm{ZnO}$ nanoparticles with fuel variation," World Journal of Nano Science and Engineering, vol. 4, pp. 21-28, 2014.

[18] A. Khorsand Zaka, W. H. Abd Majida, M. E. Abrishamib, and R. Yousefic, "X-ray analysis of $\mathrm{ZnO}$ nanoparticles by WilliamsonHall and size-strain plot methods," Solid State Sciences, vol. 13, no. 1, pp. 251-256, 2011.

[19] P. Scardi, M. Leoni, and R. Delhez, "Line broadening analysis using integral breadth methods: a critical review," Journal of Applied Crystallography, vol. 37, no. 3, pp. 381-390, 2004.

[20] J. Tauc, R. Grigorovici, and A. Vancu, "Optical properties and electronic structure of amorphous germanium," physica Status Solidi, vol. 15, no. 2, pp. 627-637, 1966.

[21] X. Fu, X. Wang, J. Long et al., "Hydrothermal synthesis, characterization, and photocatalytic properties of $\mathrm{Zn}_{2} \mathrm{SnO}_{4}$," Journal of Solid State Chemistry, vol. 182, no. 3, pp. 517-524, 2009. 

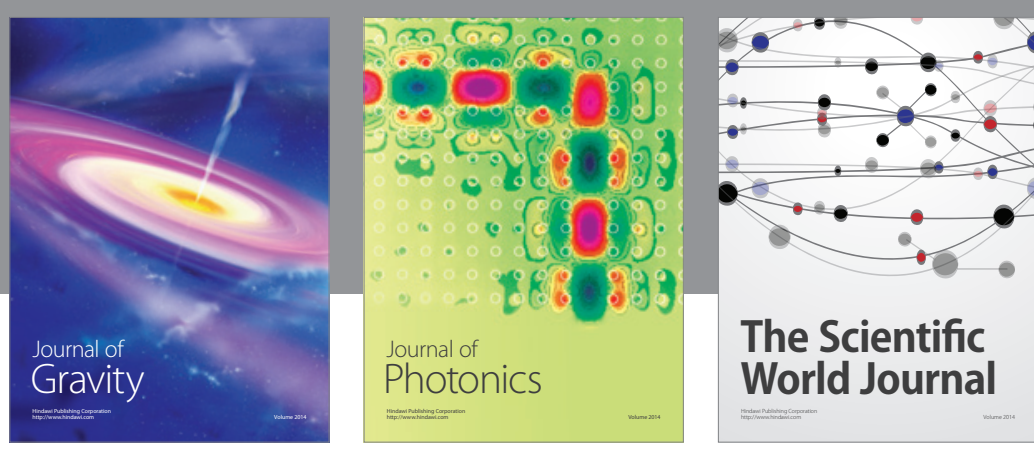

The Scientific World Journal
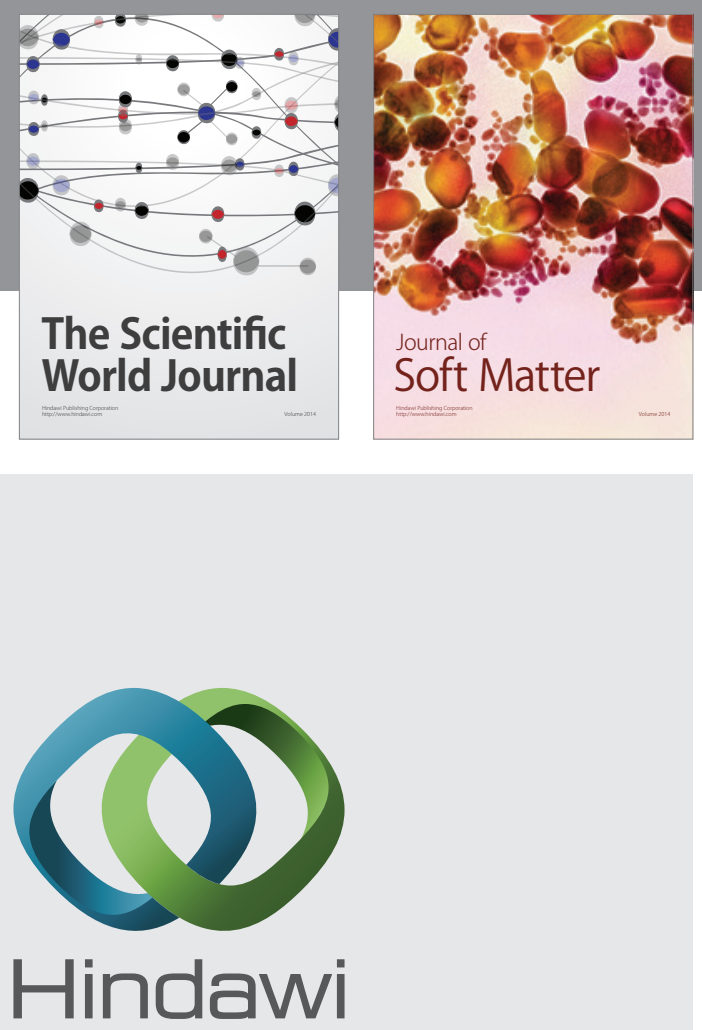

Submit your manuscripts at

http://www.hindawi.com

nternational Journal of

Statistical Mechanics
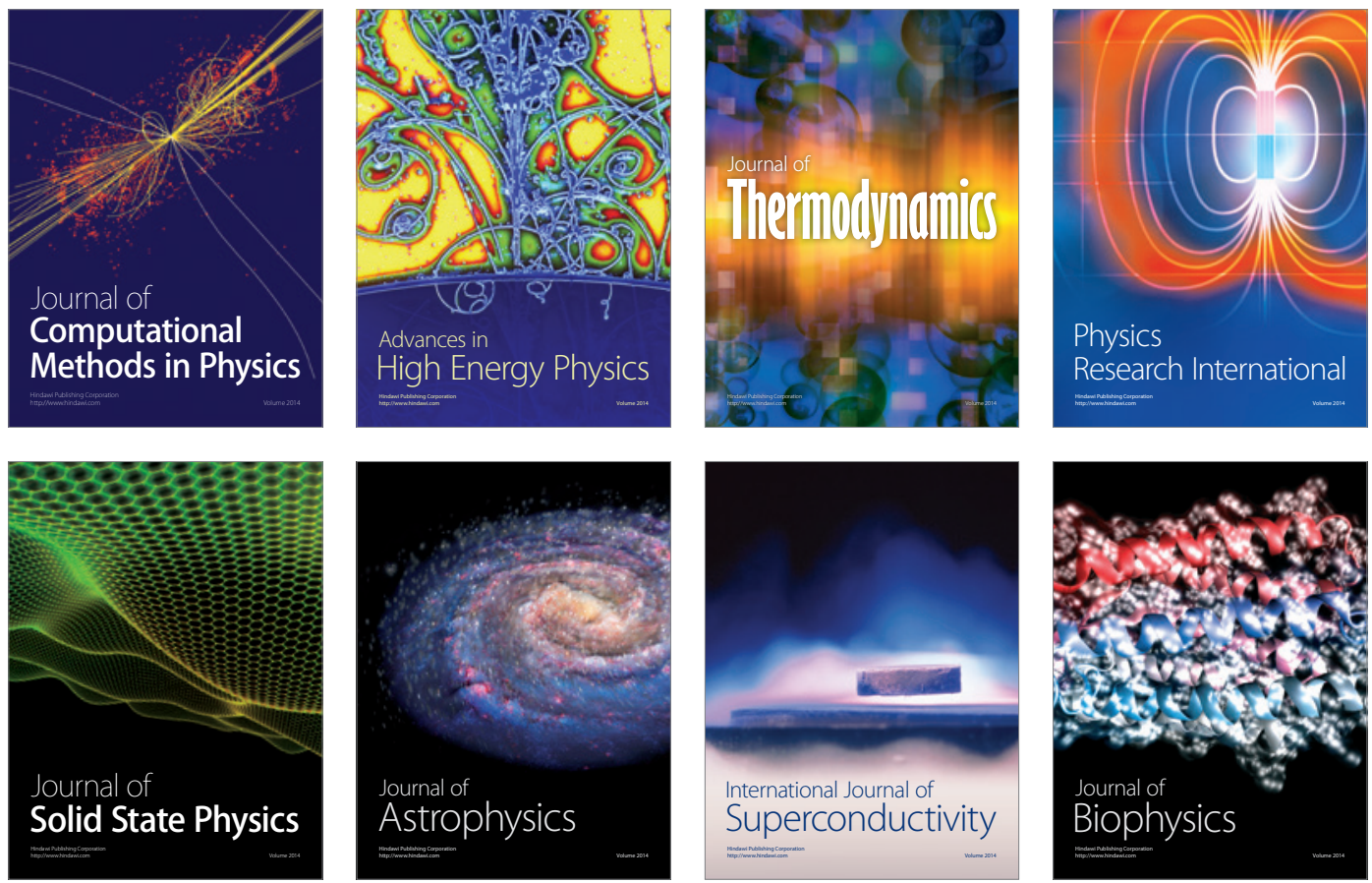
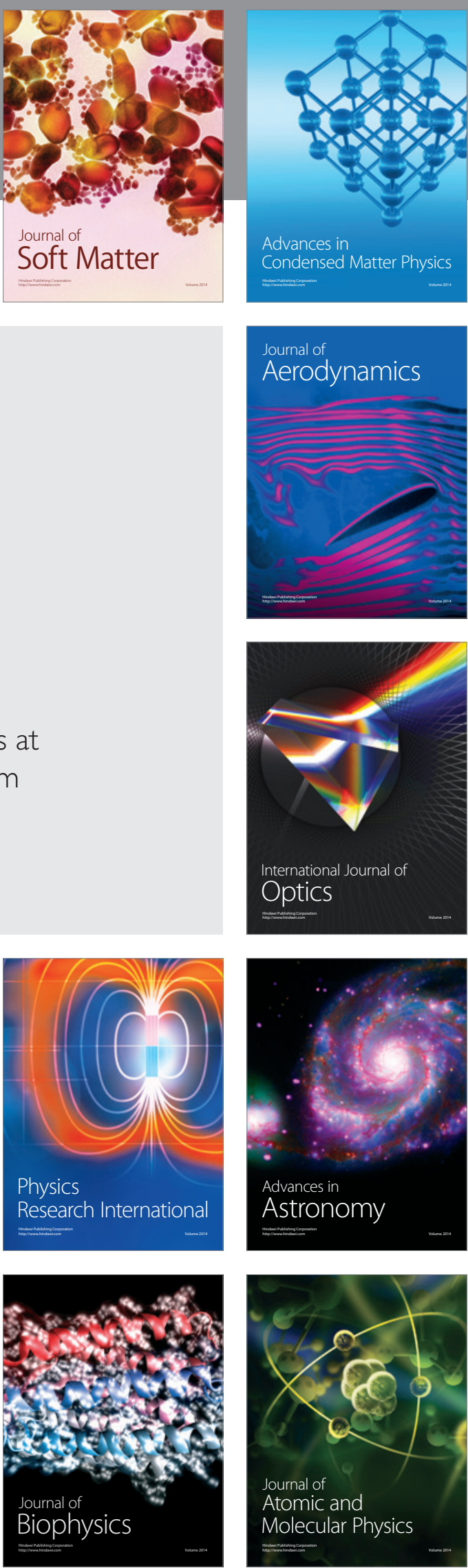